\title{
Prohibitin-2 negatively regulates AKT2 expression to promote prostate cancer cell migration
}

\author{
YONGMEI SHEN $^{1 *}$, YU GAO $^{1 *}$, HUI YUAN $^{1}$, JIASONG CAO $^{1}$, BONA JIA ${ }^{1}$, MINGMING LI $^{1}$, \\ YANFEI PENG ${ }^{2}$, XIAOLING DU ${ }^{1}$, JU ZHANG ${ }^{1}$ and JIANDANG SHI ${ }^{1}$
}

${ }^{1}$ College of Life Sciences and Bioactive Materials Key Lab of Ministry of Education, Nankai University, Tianjin 300071;
${ }^{2}$ School of Integrative Medicine, Tianjin University of Traditional Chinese Medicine, Tianjin 300193, P.R. China

Received April 5, 2016; Accepted November 21, 2017

DOI: $10.3892 / \mathrm{ijmm} .2017 .3307$

\begin{abstract}
Prostate cancer (PCa) is a leading cause of cancer-associated mortality in men; however, the factors that contribute to disease development have yet to be fully elucidated. Previous studies have suggested that prohibitin-2 (PHB2), which is a multifunctional protein that contributes to various cellular processes, is positively correlated with malignant progression of $\mathrm{PCa}$; however, the molecular mechanisms underlying the effects of PHB2 on the enhancement of cell migration have not been identified. The present study induced overexpression and knockdown of PHB2 in PCa cell lines (PC3 and DU145) with the aim of examining the effects of PHB2 on PCa cell migration via wound healing assays. The results indicated that PHB2 overexpression promoted migration of both cell lines. AKT serine/threonine kinase 2 (AKT2), which interacts with PHB2, has been reported to participate in cell migration; therefore, the present study examined the effects PHB2 overexpression and knockdown on AKT2 in PCa cells. The present study demonstrated that overexpression of PHB2 reduced the expression of AKT2, whereas PHB2 knockdown increased AKT2 expression in both PCa cell lines. In addition, knockdown of PHB2 enhanced the protein stability of AKT2. Furthermore, AKT2 overexpression resulted in a significant decrease in migration, whereas AKT2 knockdown promoted migration of PC3 and DU145 PCa cells. The combined overexpression of PHB2 and AKT2 inhibited migration of both cell lines, thus suggesting that AKT2 overexpression abolished PHB2-induced migration. Mechanistically, the present study suggested that PHB2 may promote PCa cell migration by inhibiting the expression of AKT2. These results provide information regarding the role of PHB2 in PCa migration and malignancy.
\end{abstract}

Correspondence to: Professor Jiandang Shi or Professor Ju Zhang, College of Life Sciences and Bioactive Materials Key Lab of Ministry of Education, Nankai University, 94 Weijin Road, Tianjin 300071, P.R. China

E-mail: shijd@nankai.edu.cn

E-mail: zhangju@nankai.edu.cn

*Contributed equally

Key words: prostate cancer, prohibitin 2, AKT serine/threonine kinase 2, migration

\section{Introduction}

Prostate cancer (PCa) is a major cause of morbidity and mortality among men worldwide, with recent trends indicating that younger men are being affected and that the incidence rates are increasing annually (1). PCa is also associated with other diseases, including metabolic syndrome and diabetes mellitus. As with other types of cancer, tumor metastasis is the main cause of mortality in patients with $\mathrm{PCa}$; and cell migration and invasion are two important features of metastasis and the spread of tumor cells. The processes that control migration, invasion and ultimately tumor metastasis are not yet fully understood $(2,3)$. At the molecular and cellular level, metastasizing prostate tumor cells undergo numerous alterations, including cell-cell and cell-matrix adhesion, cytoskeletal reorganization and activation of various signaling pathways. Although numerous studies have investigated cell migration and invasion, their underlying mechanisms are not yet fully understood $(4,5)$.

Prohibitin 2 (PHB2), also known as BAP37, REA and prohibitone, is one of two highly homologous inhibitins. As a multifunctional protein, PHB2 participates in numerous important cellular processes, including cell survival, apoptosis, metabolism, inflammation, gene transcription and signal transduction (6,7). PHB2 is predominantly located in the cell nucleus, mitochondria and cell membrane, and is highly expressed in PCa, liver cancer, pancreatic carcinoma and breast cancer compared with in corresponding normal tissues (8-11). These observations may be associated with the fact that PHB2 serves prominent roles in maintaining mitochondrial function, and promoting cell proliferation and survival (12-14). Furthermore, PHB2 is involved in cell growth, resistance to chemotherapy and tumor metastasis by modulating the transcriptional activity of transforming growth factor- $\beta$ in the Ras-cRaf-mitogen-activated protein kinase kinaseextracellular signal-regulated kinase signaling pathway $(15,16)$. In addition, the expression of PHB2 has been revealed to be upregulated in early invasive stages but downregulated in later stages in hepatocellular carcinoma (17). To the best of our knowledge, a single report demonstrated that knockdown of PHB2 abolished insulin-like growth factor-binding protein-6 (IGFBP-6)-induced $\mathrm{Rh} 30$ cell migration (18). In addition, relatively little is known about PHB2 and migration, which is the focus of the present study.

As a serine protein kinase, AKT serine/threonine kinase (AKT) modulates various cellular processes, including 
metabolism, proliferation, migration, apoptosis and angiogenesis by phosphorylating downstream substrates (19). AKT2 was the first gene identified in the AKT family that could change at the genomic level in diabetes patients and serve a key role in the malignant process (20-22). In PC3 PCa cells, AKT2 has been reported to inhibit cell migration and invasion by activating $\beta$-integrin. Conversely, silencing of AKT2 resulted in an increase in focal adhesion size, upregulation of microRNA-200 family expression and improvement of integrin activity, which may eventually enhance cell motility (23). In addition, AKT2 knockout enhanced cell migration by regulating the $\mathrm{Rac} / \mathrm{Pak}$ signaling pathway in mouse embryonic fibroblast cells (24). One possible reason for the participation of AKT2 in cell migration is that AKT2 upregulates K18 and vimentin expression by increasing mRNA stability, which may affect intermediate filament expression (25). Similarly, as a multifunctional protein, AKT2 is located in the mitochondria, nuclei and cell membrane, and is involved in several cellular processes, including cell cycle regulation, mitochondrial stability and cell migration. Notably, there is some overlap in the cellular processes regulated by AKT2 and PHB2, thus indicating a potential functional correlation between them.

There are many similarities in the cellular localization and function of AKT2 and PHB2. Both are located in the mitochondria, nucleus and cell membrane, which may be associated with their signal transduction function $(11,23,26)$. Localization of PHB2 in the nucleus allows it to partially interact with AKT2 in differentiated fibroblasts. In addition, there appears to be a negative correlation between AKT2 and PHB2 protein levels; AKT2-silenced cells exhibited increased levels of PHB2, whereas AKT2 overexpression resulted in decreased PHB2 expression, thus suggesting overlapping functions between the two proteins (27). In myoblasts, AKT2 negatively modulates the expression of PHB2, and exerts negative feedback regulation $(28,29)$.

Previous studies have indicated that AKT2 is a negative regulator of cell migration in $\mathrm{PCa}$, whereas $\mathrm{PHB} 2$ may be positively correlated with the malignant progression of $\mathrm{PCa}$ (23). Therefore, it may be hypothesized that a regulatory interaction between AKT2 and PHB2 exists, which is associated with migration of PCa cells. The present study demonstrated that PHB2 could significantly accelerate migration of PCa cells and negatively modulate AKT2 expression. Furthermore, knockdown of PHB2 increased the stability of AKT2 protein expression, whereas co-overexpression of PHB2 and AKT2 inhibited cell migration. These results indicated that PHB2 may promote the migration of PCa cells by inhibiting AKT2 expression.

\section{Materials and methods}

Cell culture and treatment. RWPE-1 and BPH-1 cell lines were provided as gifts from Professor Helmut Klocker (Innsbruck University School of Medicine (Innsbruck, Austria). The human PCa cell line PC3 was purchased from the Deutsche Sammlung fuer Mikroorganismen und Zellkulturen (Braunschweig, Germany) and the PCa cell line DU145 was obtained from the American Type Culture Collection (ATCC, Manassas, VA, USA). RWPE-1 cells were cultured in keratinocyte serum-free medium (ATCC) supplemented with $0.05 \mathrm{mg} / \mathrm{ml}$ bovine pituitary extract (cat. no. 0713; ScienCell, San Diego, CA, USA) and $5 \mathrm{ng} / \mathrm{ml}$ human recombinant epidermal growth factor (cat. no. 10784-015;
Gibco; Thermo Fisher Scientific, Inc., Waltham, MA, USA). The other cell lines were cultured in RPMI-1640 medium (Sigma-Aldrich; Merck KGaA, Darmstadt, Germany) supplemented with $100 \mathrm{mg} / \mathrm{ml}$ penicillin/streptomycin (HyClone; GE Healthcare Life Sciences, Logan, UT, USA) and 10\% fetal bovine serum (FBS; Gibco; Thermo Fisher Scientific, Inc.). Cells were routinely cultured in a $5 \% \mathrm{CO}_{2}$ incubator at $37^{\circ} \mathrm{C}$.

Oncomine data analysis. Oncomine is freely available to the academic research community at http://www.oncomine.org. The method was performed as described previously $(30,31)$.

RNA extraction and reverse transcription-quantitative polymerase chain reaction ( $R T-q P C R)$. Total RNA was extracted from PC3 and DU145 cells using TRIzol reagent (Invitrogen; Thermo Fisher Scientific, Inc.). RT was performed for $2 \mathrm{~h}$ at $37^{\circ} \mathrm{C}$ as described previously (32). RT-PCR reagents were purchased from Invitrogen; Thermo Fisher Scientific, Inc. (cat. no. AM1005M). The relative gene expression levels were determined using the comparative $\mathrm{Cq}$ method (33) and were normalized to the housekeeping gene hypoxanthine phosphoribosyltransferase 1 (HPRT). Primer sequences were as follows: $H P R T$, sense, 5'-TGACACTGGCAAAACAATGCA-3' and antisense, 5'-GGTCCTTTTCACCAGCAAGCT-3'; $P H B 2$, sense, 5'-ACAGAGCCATCTTCTTCAATC-3' and antisense, 5'-CTCGTTCCTCGTAGTCCAG-3'; and AKT2, sense, 5'-CCC GGTTTTATGGTGCAGAGAT-3' and antisense, 5'-GGCC GCACATCATCTCGTACAT-3'. SYBR-Green I-based realtime quantitative PCR was performed on an MJ Research DNA Engine Opticon continuous fluorescence detection system (Opticon Monitor II; MJ Research, Inc.). SYBR ${ }^{\mathrm{TM}}$-Green PCR Master Mix was obtained from Invitrogen; Thermo Fisher Scientific, Inc. (cat. no. 4309155). The thermocycling conditions were as follows: step $1,95^{\circ} \mathrm{C}$ for $5 \mathrm{~min}$; step $2,95^{\circ} \mathrm{C}$ for $30 \mathrm{sec}$; step $3,58-65^{\circ} \mathrm{C}$ for $30 \mathrm{sec}$; step $4,72^{\circ} \mathrm{C}$ for $30 \mathrm{sec}$; step 5, repeat from step 2 for 39 cycles; step $6,72^{\circ} \mathrm{C}$ for $2 \mathrm{~min}$.

Plasmids, small interfering (si)RNA and transient transfection. PHB2 or AKT2 fragments were obtained by PCR amplification of cDNA collected from PC3 cells, and were cloned into the expression vector pcDNA3.1 (Addgene, Cambridge, MA, USA).

Specific siRNA oligonucleotides targeting PHB2 and AKT2 mRNA were designed by Shanghai GenePharma Co., Ltd. (Shanghai, China). The oligonucleotide sequences were as follows: PHB2, 5'-CUGAACCCCUCUUGGAUUAAGTT-3'; PHB2 siNC, 5'-UUCUCCGAACGUGUCACGUTT-3' and AKT2, 5'-AAGAGTGGATGCGGGCTATCC-3' (34). Cell transfection was performed using Lipofectamine ${ }^{\mathrm{TM}} 3000$ (Invitrogen; Thermo Fisher Scientific, Inc.). PC3 and DU145 were seeded into 6-well plates at approximately 70-90\% confluence and transduced with Lipofectamine 3000 and plasmid/ siRNA, at a ratio of 1:1. Transfected cells were harvested after $72 \mathrm{~h}$ of transfection for RNA or protein extraction. The plasmid concentration was $2.5 \mu \mathrm{g}$ for a 6-well, and siRNA was $75 \mathrm{pmol}$.

Western blot analysis. Cells were lysed with radioimmunoprecipitation assay buffer (cat. no. 89900; Thermo Fisher Scientific, Inc.) for $30 \mathrm{~min}$ at ice to extract the total protein, then centrifuged for $10 \mathrm{~min}$ and the supernatant was aspirated. Protein was quantified using the bicinchoninic acid method. 

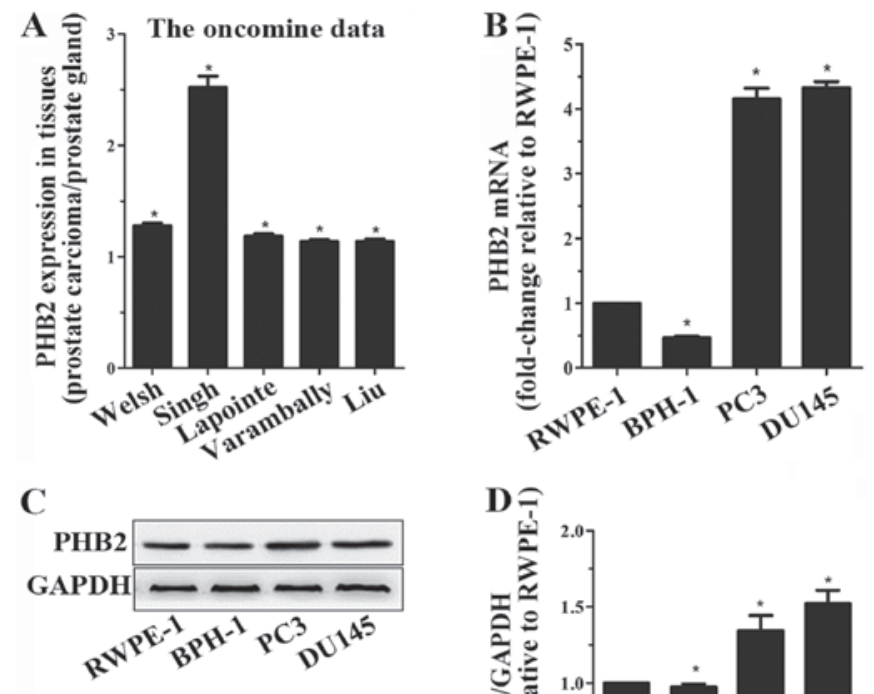

added, and after $2 \mathrm{~h}$ scratch wounds were made by scraping the cell layer in each culture plate using the tip of a sterile pipette. The cells were then washed with 1X D-Hank's buffered saline. The wounded cultures were incubated with medium containing mitomycin $(10 \mathrm{ng} / \mathrm{ml})$. Image J software $(1.47 \mathrm{v}$; National Institutes of Health, Bethesda, MD, USA) was used to calculate cell migration distance. Cell images were captured using Olympus CX41 microscope (Olympus, Tokyo, Japan) 24 h later. The experiments were performed in triplicate.

Transwell migration assay. Transwell inserts ( $8 \mu \mathrm{m}$ pore size; BD Biosciences, Franklin Lakes, NJ, USA) were used for migration assays and were placed in 24-well plates. DU145 and PC3 transfected with PHB2 and/or AKT2 were resuspended in serum-free RPMI-1640 medium in the upper chamber at 40,000 cells/well $48 \mathrm{~h}$ after transfection. RPMI-1640 medium containing $10 \%$ FBS was added to the bottom chamber. Plates were incubated for $24 \mathrm{~h}$, after which migrated cells were fixed with $4 \%$ paraformaldehyde and stained with $10 \%$ crystal violet. The stained cells were mounted and visualized in the bright field with an Olympus CX41 microscope. Positively stained cells were counted in at least 9 randomly selected microscopic fields and counted by ImageJ $1.47 \mathrm{v}$ software (National Institutes of Health).

Figure 1. PHB2 expression in prostate cancer. (A) PHB2 expression is lower in normal prostate tissues compared with in cancer tissues, as determined using data from Oncomine [Welsh (40), Singh (41), Lapointe (42), Varambally (43), Liu (44)]. (B) Reverse transcription-quantitative polymerase chain reaction analysis of $P H B 2$ mRNA in various prostate epithelial cells $(n=3)$. RWPE-1 is an immortalized human normal prostate cell line (RWPE-1), BPH-1 is a human benign prostate hyperplasia cell line, whereas DU145 and PC3 are human androgen-independent brain and bone metastastic prostate cancer cell lines. (C) Western blot analysis of PHB2 in various prostate epithelial cells. (D) Semi-quantitative analysis of (C). Data are presented as the means \pm standard deviation from three independent experiments. ${ }^{*} \mathrm{P}<0.05$ compared with normal prostate tissue or cell lines. PHB2, prohibitin-2.

Proteins extracted from PC3 and DU145 cells (30 $\mu \mathrm{g}$ protein) were separated by $10 \%$ SDS-PAGE and were transferred onto polyvinylidene fluoride membranes. The membranes were blocked in $4 \%$ skim milk powder for $1 \mathrm{~h}$ at room temperature. Antibodies against PHB2 (sc-67045; 1:1,000), AKT2 (sc-5270; 1:1,000) and GAPDH (sc-47724; 1: 5,000) (all from Santa Cruz Biotechnology, Inc., Dallas, TX, USA) were used. The membranes were incubated overnight at $4^{\circ} \mathrm{C}$. Proteins were detected using appropriate horseradish peroxidase-conjugated secondary antibodies (Bio-Rad Laboratories, Inc., Hercules, CA, USA) followed by enhanced chemiluminescence detection (Amersham; GE Healthcare Life Sciences, Little Chalfont, $\mathrm{UK})$. The secondary antibodies were incubated for $1 \mathrm{~h}$ at room temperature and the antibodies information was as follows: goat anti-rabbit IgG-HRP (sc-2004; 1:5,000); goat anti-mouse IgG-HRP (sc-2005; 1:5,000) (both from Santa Cruz Biotechnology, Inc.). ImageJ $1.47 \mathrm{v}$ software (National Institutes of Health, Bethesda, MD, YSA) was used for densitometry quantification.

Wound healing assay. A wound healing assay was performed as previously described (35). Briefly, DU145 and PC3 PCa cells were seeded into 6-well plates and were transiently transfected with the appropriate plasmids or siRNAs once cell density reached $80-90 \%$. Subsequently, mitomycin $(10 \mathrm{ng} / \mathrm{ml})$ was
Statistical analysis. Data are presented as the means \pm standard deviation. Significance was assessed using Student's paired t-test. Data between multiple groups were compared using twotailed unpaired t-test or analysis of variance. All data analyses were performed using SPSS 16.0 software (SPSS Inc., Chicago, IL, USA). $\mathrm{P}<0.05$ was considered to indicate a statistically significant difference.

\section{Results}

PHB2 expression in prostate tissues. Oncomine data demonstrated that PHB2 is highly expressed in PCa tissues compared with in normal tissues. Oncomine data demonstrated the same trend (Fig. 1A). In addition, RT-qPCR and western blot analysis were used to detect the expression levels of PHB2 in four prostate epithelial cell lines with various degrees of malignancy: RWPE-1, BPH-1, DU145 and PC3. PHB2 expression in the PCa cells, DU145 and PC3, was higher than in the RWPE-1 and BPH-1 cells (Fig. 1B-D). It is well known that the degree of malignancy is higher in DU145 and PC3 cells compared with in RWPE-1 and BPH-1 cells. These results indicated that PHB2 expression was increased in PCa cells with higher malignancy.

PHB2 promotes $P C$ a cell migration. To further investigate the association between PHB2 and PCa cell migration, pcDNA3.1-PHB2 plasmid or siPHB2 were transiently transfected into PC3 and DU145 cells, in order to examine the effects on cell migration. Transfection efficiency was assessed by RT-qPCR and western blot analysis (Fig. 2A-C). In order to determine the association between PHB2 and PCa migration, a wound healing assay was conducted in PC3 and DU145 cells with PHB2 overexpression and PHB2 knockdown. Wound healing was examined at 0 and $24 \mathrm{~h}$. The migratory ability of PC3 and DU145 cells with PHB2 overexpression was significantly enhanced, whereas PHB2 knockdown significantly reduced migration compared with in the control group within 

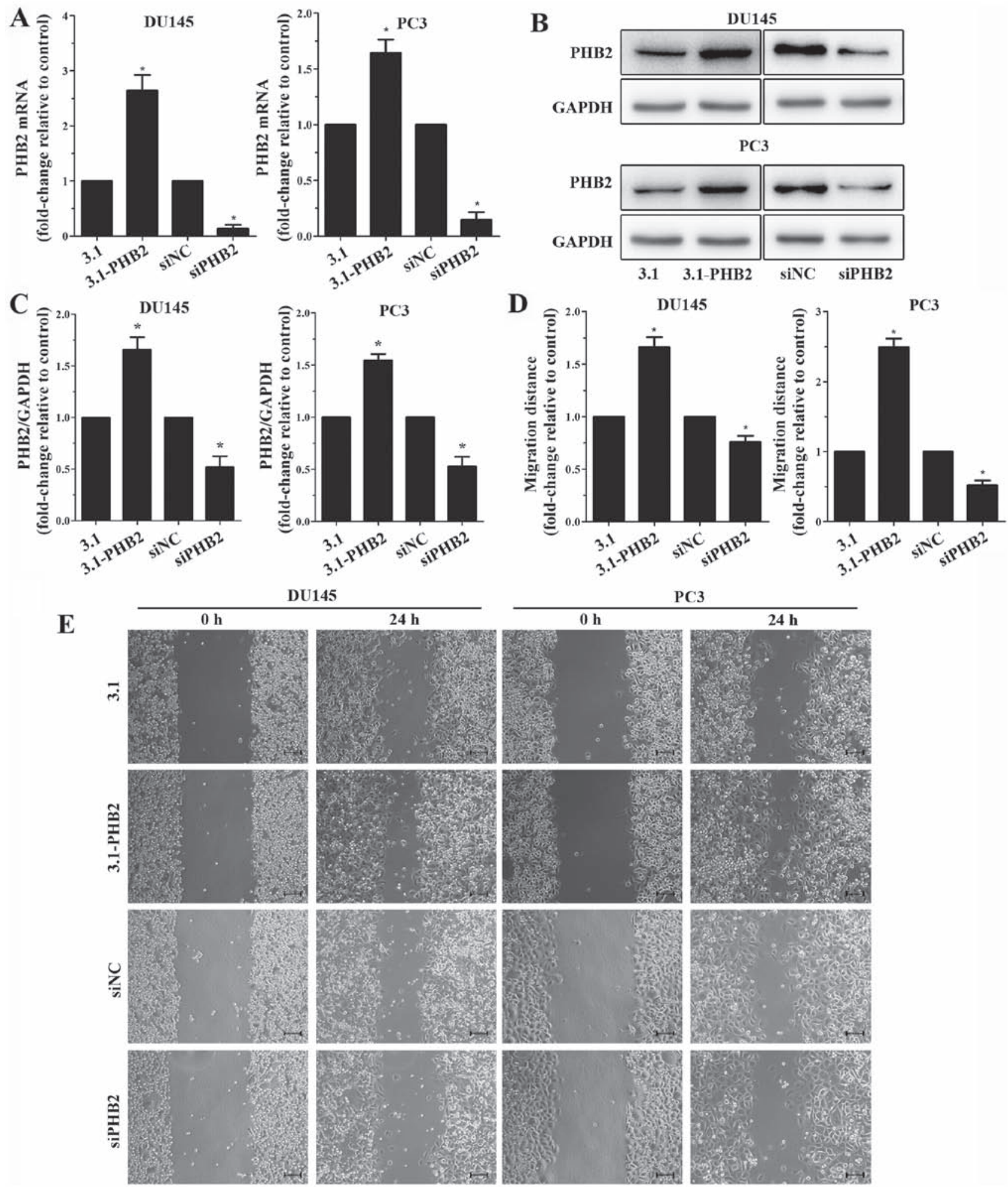

Figure 2. Effects of PHB2 on DU145 and PC3 cell migration. (A) Reverse transcription-quantitative polymerase chain reaction analysis of $P H B 2$ expression in DU145 and PC3 cells in response to overexpression or knockdown of PHB2 (n=3). (B) Western blot analysis of of PHB2 expression in DU145 and PC3 cells in response to overexpression or knockdown of PHB2 $(n=3)$. (C) Semi-quantitative analysis of (B). (D and E) Wound healing assay analysis of migration of DU145 and PC3 cells with PHB2 overexpression or knockdown (magnification, x100). Scale bar, $200 \mu \mathrm{m}$. Results of the migration assay were semi-quantified. Data are presented as the means \pm standard deviation from three independent experiments. "P $<0.05$ compared with the control. NC, negative control; PHB2, prohibitin-2; si, small interfering RNA.

$24 \mathrm{~h}$ (Fig. 2D and E). These results suggested that PHB2 may promote the migration of PC3 and DU145 PCa cells, whereas PHB2 knockdown had no effect. Therefore, PHB2 may be a positive regulator of migration in PC 3 and DU145 cells. In addi- tion, PHB2 overexpression was induced in BPH-1 cells, which have relatively lower expression levels of PHB2 compared with PC3 and DU145; the results indicated that PHB2 overexpression could promote migration of BPH-1 cells (Fig. 3). 

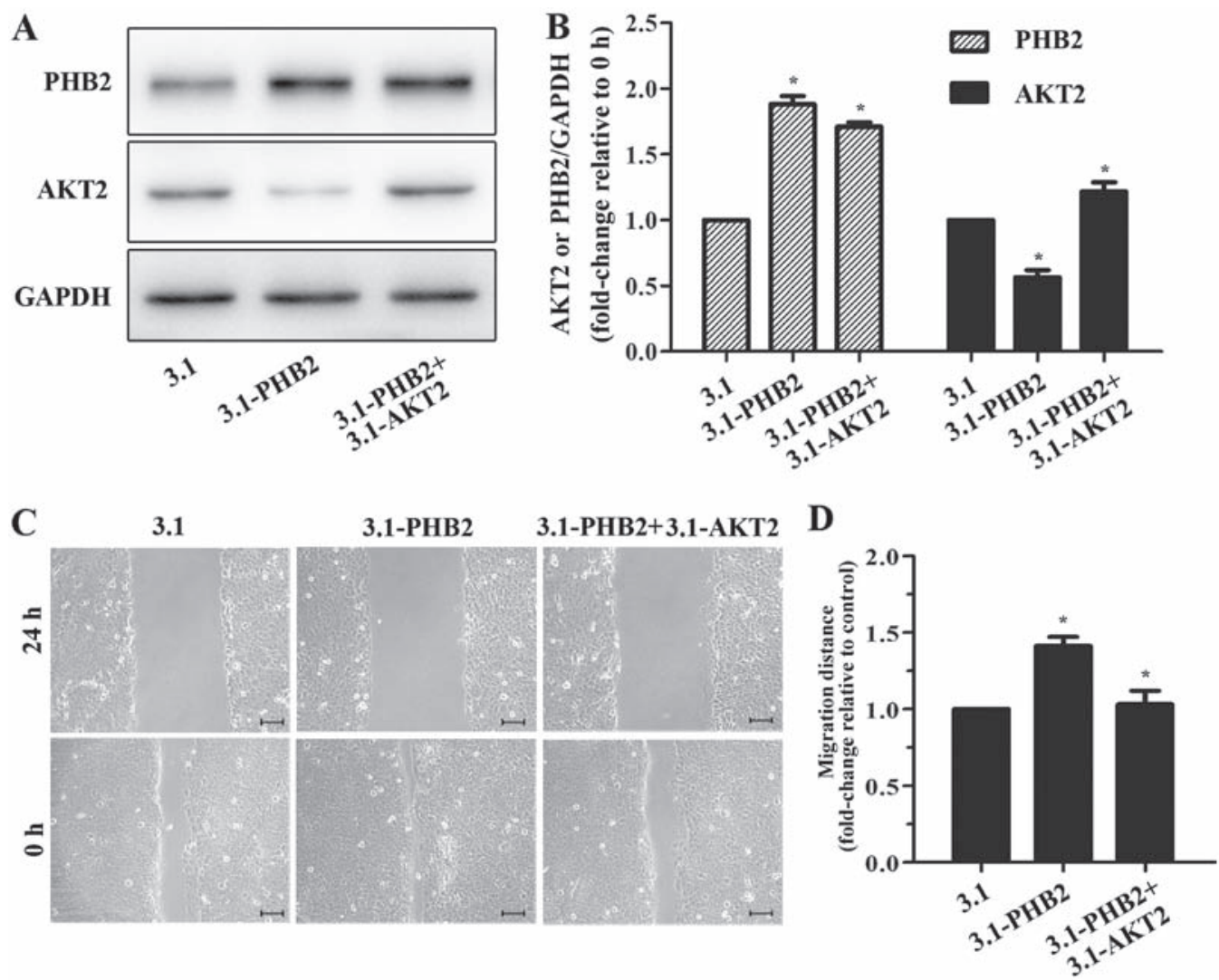

Figure 3. Effects of PHB2 on BPH-1 cell migration. (A) Western blot analysis of PHB2 expression in BPH-1 cells with PBH2 and/or AKT2 overexpression for $48 \mathrm{~h}$ $(\mathrm{n}=3)$. (B) Semi-quantitative analysis of (A). (C) Wound healing assay analysis of cell migration in BPH-1 cells with PHB2 and/or AKT2 overexpression (magnification, $\mathrm{x} 100$ ). Scale bar, $200 \mu \mathrm{m}$. (D) Semi-quantitative analysis of the relative migration distance presented in (C). Data are presented as the mean \pm standard deviation from three independent experiments. ${ }^{*} \mathrm{P}<0.05$ compared with the control. AKT2, AKT serine/threonine kinase 2; PHB2, prohibitin-2.

PHB2 inhibits AKT2 expression. To determine whether PHB2 could affect the expression of AKT2, the expression levels of AKT2 were detected by RT-qPCR and western blot analysis in DU145 and PC3 cells. As shown in Fig. 4, the mRNA expression levels of $A K T 2$ were decreased in PC3 and DU145 cells with PHB2 overexpression; however, they were increased in response to PHB2 knockdown for 24 h (Fig. 4A). Notably, western blotting indicated that AKT2 expression was markedly decreased in cells with PHB2 overexpression (Fig. 4B and C); these results suggested that AKT2 expression was regulated by PHB2. In addition, overexpression of PHB2 could downregulate the protein expression levels of $\mathrm{AKT} 2$ in $\mathrm{BPH}-1$ cells (Fig. 3A and B).

Since PHB2 may promote cell migration and inhibit AKT2 expression, it was hypothesized that overexpression of AKT2 may reduce $\mathrm{PHB} 2$-induced migration. Therefore, cells were cotransfected with PHB2 and AKT2 vectors/siRNAs, and the effects on migration were detected. The protein expression levels of PHB2 and AKT2 were significantly increased following cotransfection with overexpression vectors, and were decreased following cotransfection with siRNAs (Fig. 5A). Results of the wound healing assay indicated that the migration of PC3 and DU145 cells with PHB2 and AKT2 co-overexpression was significantly decreased after $24 \mathrm{~h}$ compared with in the control group; however, knockdown of both AKT2 and PHB2 enhanced migration compared with in the control group within $24 \mathrm{~h}$ (Fig. 5B and C). The results of the wound healing assay were confirmed by a Transwell migration assay (Fig. 5D and E). In addition, these findings were verified in BPH-1 cells (Fig. 3C and D). In conclusion, AKT2 may reduce PHB2-induced migration, thus suggesting that PHB2 promotes the migration of PC3 and DU145 PCa cells by inhibiting the expression of AKT2.

\section{Discussion}

Previous studies have reported that PHB2 is highly expressed in various types of cancer, including liver, breast and bladder cancer; and likely promotes or inhibits neoplastic progression depending on PHB2 transcription, post-translational modifications and translation in various tumor types $(6,10,36)$. PHB2 is a multifunctional protein that serves diverse functions depending on cellular localization. The transportation of PHB2 into the nucleus and cytoplasm may be crucial for its 'functional shift'. It has previously been reported that knockdown of PHB2 abolishes IGFBP-6-induced Rh30 cell migration (18); however, how $\mathrm{PHB} 2$ participates in the progression of $\mathrm{PCa}$ remains unclear, and reports that examine the association between PHB2 and cell migration are currently lacking. We found that PHB2 expression was increased in $\mathrm{PCa}$ cells with higher malignancy (37). Therefore, in the present study, wound healing assays were used to examine cell migration; the results indicated that cell migration was enhanced upon transfection with a PHB2 overexpression plasmid in DU145, PC3 and BPH-1 cells, whereas it was reduced upon PHB2 siRNA transfection. These data suggested that PHB2 

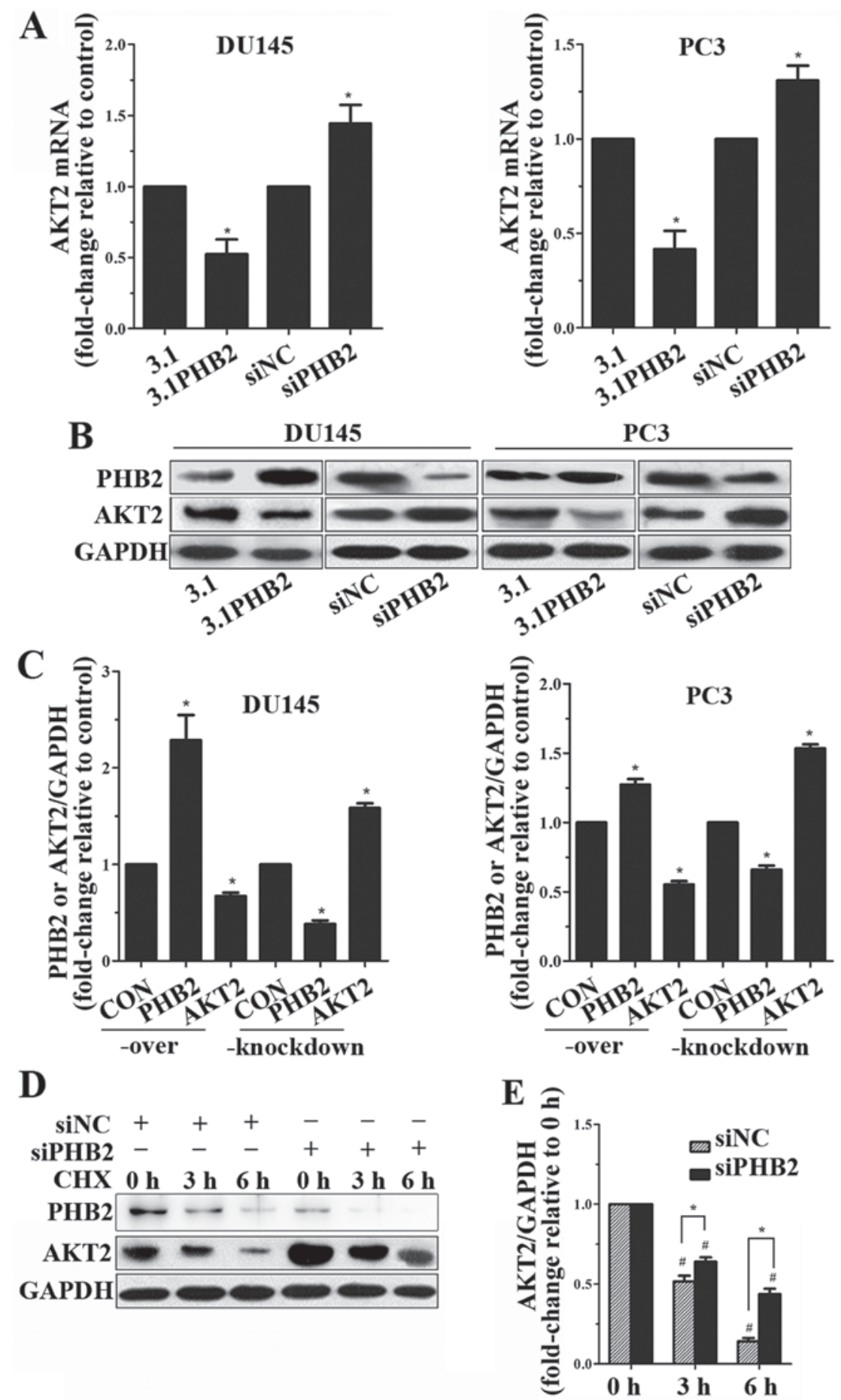

Figure 4. Expression of AKT2 following overexpression or knockdown of PHB2 in DU145 and PC3 cells. (A) Reverse transcription-quantitative polymerase chain reaction analysis of AKT2 expression in DU145 and PC3 cells with overexpression or knockdown of PHB2 (n=3). (B) Western blot analysis of AKT2 expression in DU145 and PC3 cells transfected with pcDNA3.1-PHB2 or siPHB2. (C) Semi-quantitative analysis of (B). (D) Western blot analysis of the expression of AKT2 in cells transfected with siPHB2 or the control, and treated with CHX at various time points in PC3 cells to detect AKT2 stability. GAPDH was used as a loading control. (E) Semi-quantitative analysis of (D). Data are presented as the means \pm standard deviation from three independent experiments. "P $<0.05$ compared with the control; ${ }^{\text {P }} \mathrm{P}<0.05$ compared with $0 \mathrm{~h}$. AKT2, AKT serine/threonine kinase 2; CHX, cycloheximide; NC, negative control; PHB2, prohibitin-2; si, small interfering RNA.

may be considered a positive regulatory factor in PCa cell migration.

AKT2 is a promigratory kinase that is well defined in breast cancer (38). However, unlike in breast cancer, AKT2 functions as a negative regulator of cell migration and invasion in PC3 PCa cells $(23,24,39)$. Cariaga-Martinez et al reported that AKT2 ablation increased migration of PC3 cells (26). The present study hypothesized that a relationship between PHB2 and AKT2 may exist. The results indicated that overexpression of PHB2 reduced the protein expression levels of AKT2. Conversely, knockdown of PHB2 increased the expression of AKT2 in DU145 and PC3 cells. In addition, the stability 
A

DU145

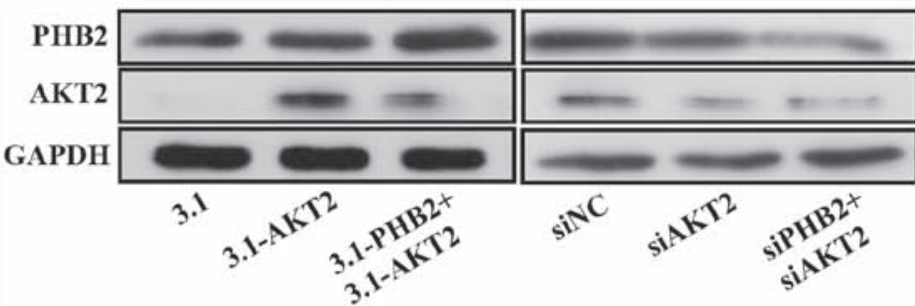

PC3

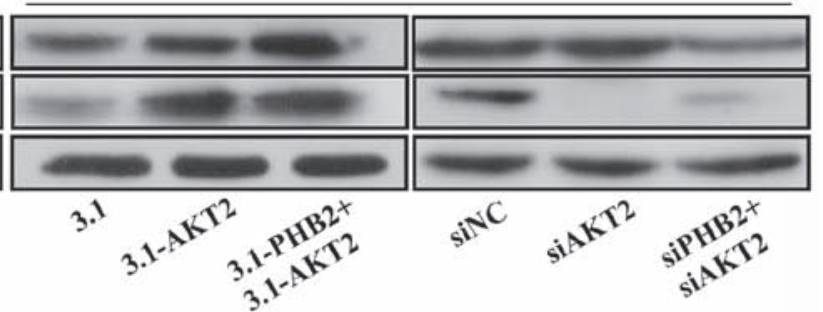

B 3.1 3.1-AKT2

3.1-PHB2+3.1-AKT2

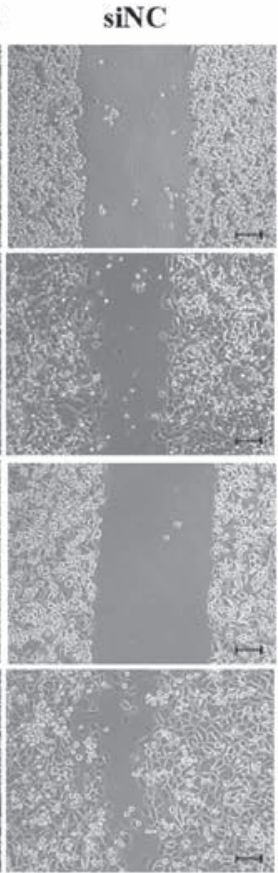

siAKT2 siPHB2+siAKT2
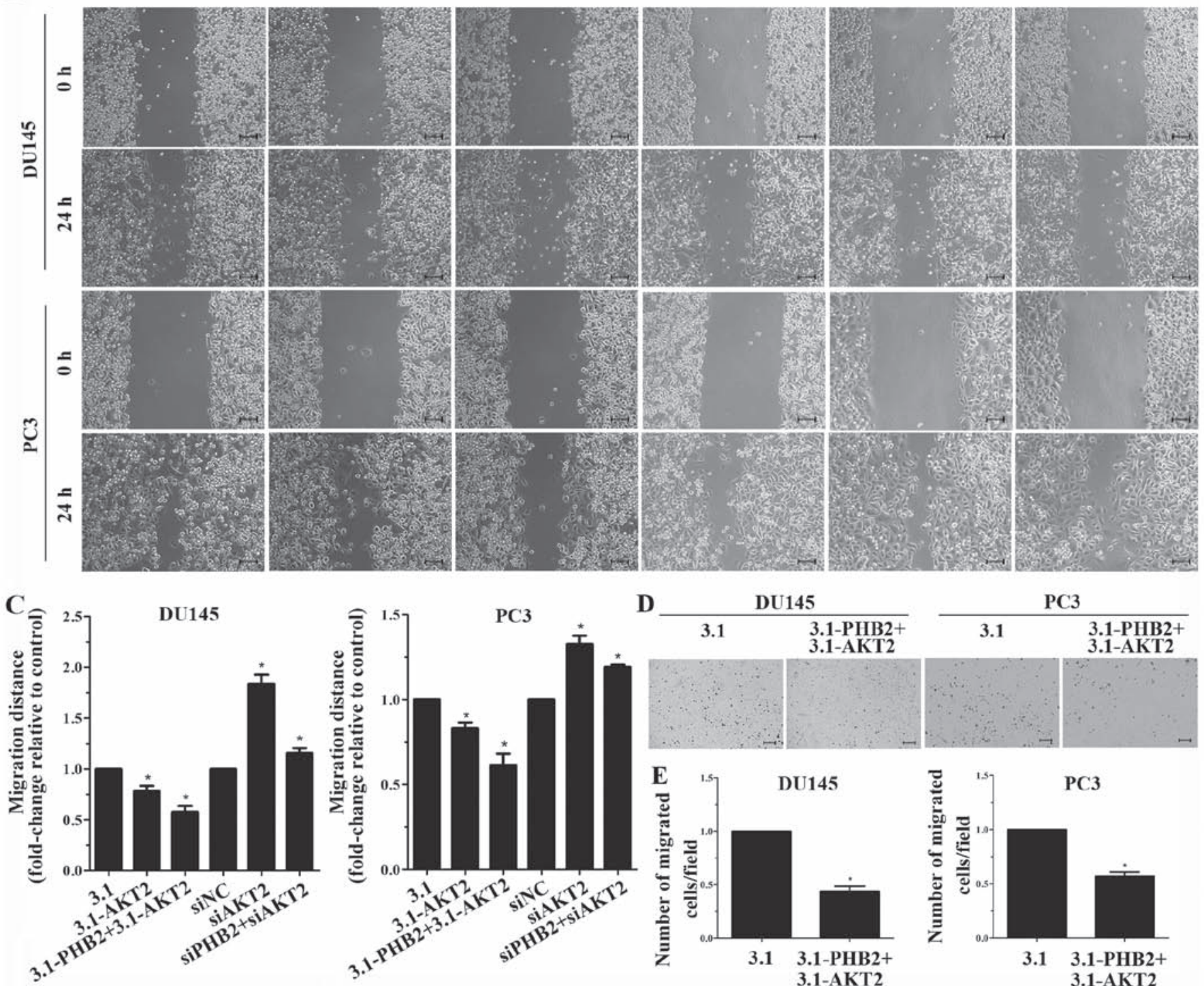

D

DU145
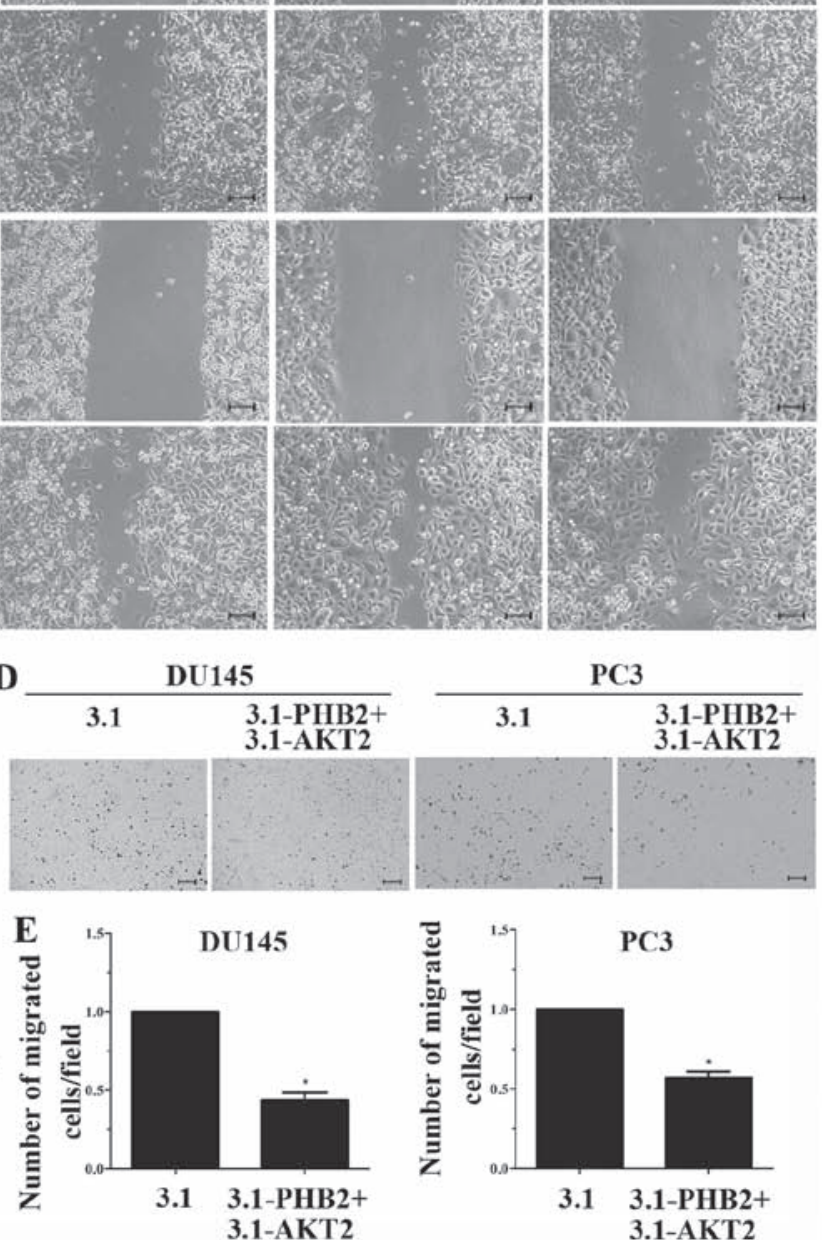

Figure 5. Effects of PHB2 and AKT2 co-overexpression on DU145 and PC3 cell migration. (A) Western blot analysis of PHB2 and AKT2 expression in DU145 and PC 3 cells with AKT2 and/or PHB2 overexpression or knockdown (n=3). (B) Wound healing assay analysis of DU145 and PC3 cell migration in response to AKT2 and/or PHB2 overexpression or knockdown (magnification, x100). Scale bar, $200 \mu \mathrm{m}$. (C) Semi-quantitative analysis of the relative migration distance presented in (B). (D) Transwell invasion assay demonstrated that DU145 and PC3 cells cotransfected with PHB2 and AKT2 were less invasive than the control group cells (magnification, x100). Scale bar, $200 \mu \mathrm{m}$. (E) Semi-quantitative analysis of (D). Data are presented as the means \pm standard deviation from three independent experiments. " $\mathrm{P}<0.05$ compared with the control.AKT2, AKT serine/threonine kinase 2; NC, negative control; PHB2, prohibitin-2; si, small interfering RNA.

of AKT2 expression was increased in PCa cells with PHB2 knockdown. These findings suggested that PHB2-mediated cell migration may be regulated by AKT2. Potentially, AKT2 may counteract PHB2-induced migration, whereas PHB2 may promote cell migration by inhibiting the expression of AKT2 in PC3 and DU145 cells. Furthermore, the present study indicated that co-overexpression of PHB2 and AKT2 signifi- cantly decreased migration of PCa cells, which supports our hypothesis. These results are in agreement with those reported in muscle cells, in which feedback regulation between AKT2 and PHB2 maintained a dynamic balance (27).

At present, the mortality rate of $\mathrm{PCa}$ continues to rise each year in China, thus underscoring the importance of understanding the pathogenesis of PCa. PCa morbidity is affected by 
complications that arise from tumor invasion, including bone and lymphatic metastases, which can ultimately lead to mortality. Therefore, understanding the process of $\mathrm{PCa}$ is of clinical significance. While PHB2 is known to promote PCa progression, its role in PCa migration has not been well studied. The present study demonstrated that PHB2 could promote cell migration, and revealed that AKT2 was negatively regulated by PHB2 in $\mathrm{PCa}$. The present study provides information regarding the function of PHB2 in the pathological process of PCa migration. These findings may potentially lay the foundation for designing targeted drugs that have clinical value in the treatment of PCa.

\section{Acknowledgements}

The authors would like to thank Professor Helmut Klocker (Innsbruck University School of Medicine) for the gift of RWPE-1 and BPH-1 cells. The present study was funded by the National Natural Science Foundation of China (nos. 81370859 and 81572784) and the Tianjin Municipal Science and Technology Commission (nos. 12ZCDZSY17000 and 15JCYBJC50900).

\section{References}

1. Friedl P and Wolf K: Plasticity of cell migration: A multiscale tuning model. J Cell Biol 188: 11-19, 2010.

2. Martin NE, Mucci LA, Loda M and Depinho RA: Prognostic determinants in prostate cancer. Cancer J 17: 429-437, 2011.

3. Kim SH, Hwang KA, Shim SM and Choi KC: Growth and migration of $\mathrm{LNCaP}$ prostate cancer cells are promoted by triclosan and benzophenone-1 via an androgen receptor signaling pathway. Environ Toxicol Pharmacol 39: 568-576, 2015.

4. Quail DF and Joyce JA: Microenvironmental regulation of tumor progression and metastasis. Nat Med 19: 1423-1437, 2013.

5. Yilmaz M and Christofori G: Mechanisms of motility in metastasizing cells. Mol Cancer Res 8: 629-642, 2010.

6. Thuaud F, Ribeiro N, Nebigil CG and Désaubry L: Prohibitin ligands in cell death and survival: Mode of action and therapeutic potential. Chem Biol 20: 316-331, 2013.

7. Kowno M, Watanabe-Susaki K, Ishimine H, Komazaki S, Enomoto K, Seki Y, Wang YY, Ishigaki Y, Ninomiya N, Noguchi TA, et al: Prohibitin 2 regulates the proliferation and lineage-specific differentiation of mouse embryonic stem cells in mitochondria. PLoS One 9: e81552, 2014.

8. Yoshimaru T, Komatsu M, Matsuo T, Chen YA, Murakami Y, Mizuguchi K, Mizohata E, Inoue T, Akiyama M, Yamaguchi R, et al: Targeting BIG3-PHB2 interaction to overcome tamoxifen resistance in breast cancer cells. Nat Commun 4: 2443, 2013.

9. Chowdhury I, Garcia-Barrio M, Harp D, Thomas K, Matthews R and Thompson WE: The emerging roles of prohibitins in folliculogenesis. Front Biosci (Elite Ed) 4: 690-699, 2012.

10. Sievers C, Billig G, Gottschalk K and Rudel T: Prohibitins are required for cancer cell proliferation and adhesion. PLoS One 5: e12735, 2010.

11. Yurugi $\mathrm{H}$ and Rajalingam $\mathrm{K}$ : A role for prohibitin in mast cell activation: Location matters. Sci Signal 6: pe29, 2013.

12. Cheng J, Gao F, Chen X, Wu J, Xing C, Lv Z, Xu W, Xie Q, Wu L, Ye S, et al: Prohibitin-2 promotes hepatocellular carcinoma malignancy progression in hypoxia based on a label-free quantitative proteomics strategy. Mol Carcinog 53: 820-832, 2014.

13. Pabona JM, Velarde MC, Zeng Z, Simmen FA and Simmen RC: Nuclear receptor co-regulator Krüppel-like factor 9 and prohibitin 2 expression in estrogen-induced epithelial cell proliferation in the mouse uterus. J Endocrinol 200: 63-73, 2009.

14. Van Aken O, Whelan J and Van Breusegem F: Prohibitins: Mitochondrial partners in development and stress response. Trends Plant Sci 15: 275-282, 2010.

15. Polier G, Neumann J, Thuaud F, Ribeiro N, Gelhaus C, Schmidt H, Giaisi M, Köhler R, Müller WW, Proksch P, et al: The natural anticancer compounds rocaglamides inhibit the Raf-MEK-ERK pathway by targeting prohibitin 1 and 2 . Chem Biol 19: 1093-1104, 2012.
16. Zhu B,Zhai J,Zhu H and Kyprianou N: Prohibitin regulates TGF- $\beta$ induced apoptosis as a downstream effector of Smad-dependent and -independent signaling. Prostate 70: 17-26, 2010.

17. Chen RX, Song HY, Dong YY, Hu C, Zheng QD, Xue TC, Liu XH, Zhang Y, Chen J, Ren ZG, et al: Dynamic expression patterns of differential proteins during early invasion of hepatocellular carcinoma. PLoS One 9: e88543, 2014.

18. Fu P, Yang $\mathrm{Z}$ and Bach LA: Prohibitin-2 binding modulates insulin-like growth factor-binding protein-6 (IGFBP-6)-induced rhabdomyosarcoma cell migration. J Biol Chem 288: 29890-29900, 2013.

19. Vivanco I, Chen ZC, Tanos B, Oldrini B, Hsieh WY, Yannuzzi N, Campos C and Mellinghoff IK: A kinase-independent function of AKT promotes cancer cell survival. eLife 3: e03751, 2014.

20. Kang W, Tong JHM, Lung RWM, Dong Y, Yang W, Pan Y, Lau KM, Yu J, Cheng AS and To KF: let-7b/g silencing activates AKT signaling to promote gastric carcinogenesis. J Transl Med 12: 281, 2014.

21. Liang JW, Shi ZZ, Shen TY, Che X, Wang Z, Shi SS, Xu X, Cai Y, Zhao P, Wang CF, et al: Identification of genomic alterations in pancreatic cancer using array-based comparative genomic hybridization. PLoS One 9: e114616, 2014.

22. Chin YR, Yuan X, Balk SP and Toker A: PTEN-deficient tumors depend on AKT2 for maintenance and survival. Cancer Discov 4: 942-955, 2014.

23. Virtakoivu R, Pellinen T, Rantala JK, Perälä M and Ivaska J: Distinct roles of AKT isoforms in regulating $\beta 1$-integrin activity, migration, and invasion in prostate cancer. Mol Biol Cell 23: 3357-3369, 2012.

24. Zhou GL, Tucker DF, Bae SS, Bhatheja K, Birnbaum MJ and Field J: Opposing roles for Akt1 and Akt 2 in Rac/Pak signaling and cell migration. J Biol Chem 281: 36443-36453, 2006.

25. Fortier AM, Van Themsche C, Asselin E and Cadrin M: Akt isoforms regulate intermediate filament protein levels in epithelial carcinoma cells. FEBS Lett 584: 984-988, 2010.

26. Cariaga-Martinez AE, López-Ruiz P, Nombela-Blanco MP, Motiño O, González-Corpas A, Rodriguez-Ubreva J, Lobo MV Cortés MA and Colás B: Distinct and specific roles of AKT1 and AKT2 in androgen-sensitive and androgen-independent prostate cancer cells. Cell Signal 25: 1586-1597, 2013.

27. Héron-Milhavet L, Mamaeva D, Rochat A, Lamb NJ and Fernandez A: Akt2 is implicated in skeletal muscle differentiation and specifically binds Prohibitin2/REA. J Cell Physiol 214: 158-165, 2008.

28. Gardner S, Anguiano M and Rotwein P: Defining Akt actions in muscle differentiation. Am J Physiol Cell Physiol 303: C1292-C1300, 2012.

29. Matheny RW Jr and Adamo ML: Effects of PI3K catalytic subunit and Akt isoform deficiency on mTOR and p70S6K activation in myoblasts. Biochem Biophys Res Commun 390: 252-257, 2009.

30. Rhodes DR, Kalyana-Sundaram S, Mahavisno V, Varambally R, Yu J, Briggs BB, Barrette TR, Anstet MJ, Kincead-Beal C, Kulkarni P, et al: Oncomine 3.0: genes, pathways, and networks in a collection of 18,000 cancer gene expression profiles. Neoplasia 9: 166-180, 2007.

31. Rhodes DR, Yu J, Shanker K, Deshpande N, Varambally R, Ghosh D, Barrette T, Pandey A and Chinnaiyan AM: ONCOMINE: a cancer microarray database and integrated datamining platform. Neoplasia 6: 1-6, 2004.

32. Zhang Z, Wang L, Mei M, Zhu Y, Du X, Lee C, Park I, Zhang J and Shi J: Both nongenomic and genomic effects are involved in estradiol's enhancing the phenotype of smooth muscle cells in cultured prostate stromal cells. Prostate 70: 317-332, 2010.

33. Livak KJ and Schmittgen TD: Analysis of relative gene expression data using real-time quantitative PCR and the 2(-Delta Delta C(T)) Method. Methods 25: 402-408, 2001.

34. Héron-Milhavet L, Franckhauser C, Rana V, Berthenet C, Fisher D, Hemmings BA, Fernandez A and Lamb NJ: Only Akt1 is required for proliferation, while Akt2 promotes cell cycle exit through p21 binding. Mol Cell Biol 26: 8267-8280, 2006.

35. Yarrow JC, Perlman ZE, Westwood NJ and Mitchison TJ: A high-throughput cell migration assay using scratch wound healing, a comparison of image-based readout methods. BMC Biotechnol 4: 21-21, 2004.

36. Artal-Sanz M and Tavernarakis N: Prohibitin and mitochondrial biology. Trends Endocrinol Metab 20: 394-401, 2009.

37. Du XL, Yu L, Ning ZC, et al: Estrogen receptor inhibitor, REA, have an effect on proliferation and migration in prostate cancer cells. Acta Scientiarum Naturalium Universitatis Nankaiensis 46: 36-43, 2013. 
38. Irie HY, Pearline RV, Grueneberg D, Hsia M, Ravichandran P, Kothari N, Natesan S and Brugge JS: Distinct roles of Akt1 and Akt2 in regulating cell migration and epithelial-mesenchymal transition. J Cell Biol 171: 1023-1034, 2005.

39. Dillon RL, Marcotte R, Hennessy BT, Woodgett JR, Mills GB and Muller WJ: Akt1 and akt2 play distinct roles in the initiation and metastatic phases of mammary tumor progression. Cancer Res 69: 5057-5064, 2009.

40. Welsh JB, Sapinoso LM, Su AI, Kern SG, Wang-Rodriguez J, Moskaluk CA, Frierson HF Jr and Hampton GM: Analysis of gene expression identifies candidate markers and pharmacological targets in prostate cancer. Cancer Res 61: 5974-5978, 2001.

41. Singh D, Febbo PG, Ross K, Jackson DG, Manola J, Ladd C, Tamayo P, Renshaw AA, D'Amico AV, Richie JP, et al: Gene expression correlates of clinical prostate cancer behavior. Cancer Cell 1: 203-209, 2002.
42. Lapointe J, Li C, Higgins JP, van de Rijn M, Bair E, Montgomery K, Ferrari M, Egevad L, Rayford W, Bergerheim U, Ekman P, et al: Gene expression profiling identifies clinically relevant subtypes of prostate cancer. Proc Natl Acad Sci USA 101: 811-816, 2004

43. Varambally S, Yu J, Laxman B, Rhodes DR, Mehra R, Tomlins SA, Shah RB, Chandran U, Monzon FA, Becich MJ, Wei JT, et al: Integrative genomic and proteomic analysis of prostate cancer reveals signatures of metastatic progression. Cancer Cell 8: 393-406, 2005.

44. Liu P, Ramachandran S, Ali Seyed M, Scharer CD, Laycock N, Dalton WB, Williams H, Karanam S, Datta MW, Jaye DL and Moreno CS: Sex-determining region $\mathrm{Y}$ box 4 is a transforming oncogene in human prostate cancer cells. Cancer Res 66: 4011-4019, 2006 